Recepción: 20 / 04 / 2017

Aceptación: 20 / 05 / 2017

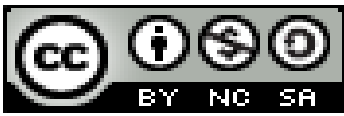

Ciencias Sociales

Publicación: 15 / 07 / 2017

\title{
La religiosidad y la arquitectura en la colonia y la república
}

\section{The religiosity and the architecture in the colony and the republic}

\section{Religião e arquitetura na colônia e da república}

\author{
Parsival E. Castro-Pita ${ }^{\text {I }}$ \\ parsival.castrop@ug.edu.ec \\ Ivetheyamel Morales-Vergara II \\ ivetheyamel.moralesv.@ug.edu.ec \\ Ivonne A. Rendon-Jaluff III \\ ivonne.rendonj@ug.edu.ec
}

Correspondencia: parsival.castrop@ug.edu.ec

Magister en Docencia y Gerencia en Educación Superior; Diploma Superior en Diseño Curricular por Competencias; Arquitecto Urbanista; Universidad de Guayaquil, Guayaquil, Ecuador.

II. Magister en Administración de Empresas con Mención en Marketing; Magister en Docencia y Gerencia en Educación Superior; Diploma Superior en Docencia y Evaluación en la Educación Superior; Arquitecta; Universidad de Guayaquil, Guayaquil, Ecuador.

III. Diploma Superior en Diseño Curricular por Competencias; Arquitecta; Universidad Guayaquil, Guayaquil, Ecuador. 


\section{Resumen}

La construcción de las ciudades americanas, como las conocemos hoy, fue un proceso propio de la colonización y la instauración de la república, pasando por los diferentes hechos naturales que afectaron cada una de las ciudades. Ahora bien, el proceso de colonización no sería el mismo sin la imposición, por distintas vías, de la religión católica; de allí que la construcción de la ciudad está íntimamente ligada a las características o relevancia comercial o productiva en la época y a la religión. Es por ello que observamos una complexión de la ciudad colonial, girante alrededor de las iglesias, catedrales, capillas, etc. distinto a los asentamientos aborígenes establecidos en torno a cerros y ríos. En este trabajo se realiza una revisión bibliográfica para caracterizar las principales estructuras denominadas "influyentes" en las principales ciudades del Ecuador y como están siempre ligadas a la religiosidad reinante en la época colonial, que de una u otra forma continúa incidiendo en la organización de la ciudad actual.

Palabras Clave: Religiosidad; colonia; república; arquitectura. 


\begin{abstract}
The construction of American cities, as we know them today, was a process of colonization and establishment of the republic, through the different natural events that affected each of the cities. Now, the process of colonization would not be the same without the imposition, by different ways, of the catholic religion; Hence the construction of the city is intimately linked to the characteristics or commercial or productive relevance at the time and to religion. That is why we observe a complexion of the colonial city, revolving around the churches, cathedrals, chapels, etc. Distinct from the aboriginal settlements established around hills and rivers. In this work a bibliographic review is carried out to characterize the main structures known as "influential" in the main cities of Ecuador and as they are always linked to the religiousness reigning in colonial times, which in one way or another continues influencing the organization of actual city.
\end{abstract}

Keywords: Religiosity; colony; republic; architecture. 


\section{Resumo}

A construção de cidades americanas, como sabemos hoje, foi um processo adequado de colonização eo estabelecimento da República, através dos diferentes eventos naturais que afetam cada uma das cidades. No entanto, o processo de colonização não seria o mesmo sem a imposição, de várias formas, a religião católica; portanto, a construção da cidade está intimamente ligado às características ou relevância comercial ou produtiva na idade e religião. É por isso que vemos uma compilação da cidade colonial, girando em torno de igrejas, catedrais, capelas, etc. outros assentamentos aborígenes estabelecida em torno de colinas e rios. Este trabalho apresenta uma revisão da literatura foi realizada para caracterizar as principais estruturas chamadas "influente" nas principais cidades do Equador como eles estão sempre ligados à religião predominante nos tempos coloniais, que de uma forma ou de outra influenciar continuamente a organização cidade atual.

Palavras chave: Religiosidade; colónia; república; arquitetura. 


\section{Introducción}

En los procesos instaurados en los siglos XVI y XVII, aparecen las adoraciones de varios cerros donde los indios declaraban que se expresaba la gracia de los dioses. En Manabí, la mayor parte de las sillas de piedra en $\mathrm{U}$, se encontraron repartidas por las crestas de cinco cerros cercanos a la actual ciudad de Manta. Estos son: Cerro de Hojas, Cerro Jaboncillo, Cerro Jupa, Cerro Agua Nueva, y Cerro Montecristi. Con el avance de la conquista, los pobladores terminaron convenciéndose que, en vez de sus dioses, los cerros estaban poblados por demonio!

Como lo indica (Laviana), El 11 de julio de 1787, el Obispo de Quito, Blas Sobrino y Minayo, dicta su sentencia en la que dispone que

en cuanto a los ídolos, materiales e instrumento de su infidelidad, idolatría y hechizo, se ordena al cura que en un día festivo y de plena concurrencia de su feligresía, después de haberla platicado, haga se quemen a vista de todo su pueblo, en medio de la plaza de él, con asistencia del teniente a quien pasará oficio, a fin de que se contenga cualquier movimiento imprevisto del pueblo con su autoridad (pag. 112)

Es así como la colonia comienza a dibujar la ciudad, en función a una nueva religiosidad y la adoración de un Dios nuevo para los indios. Se requirió no sólo la construcción de las figuras o imágenes de este "nuevo Dios" y de los nuevos ídolos, sino también la construcción de nuevos templos y nuevas estructuras, con materiales y formas diferentes a las conocidas en estas latitudes, que además permitieran romper con los esquemas religiosos o de organización social conocidos hasta ese momento. 
Un actor fundamental en la generación de un nuevo orden social fue la iglesia católica, que por medio de los sacerdotes, eran la "mano derecha" de la corona durante la conquista de América.

Después de la colonia, en la independencia, la masonería jugó un papel fundamental, incorporándose elementos arquitectónicos de esta en la vida de Ecuador. Sin pretender afirmar que la Independencia americana es una obra exclusivamente masónica, sin embargo, se puede constatar en diversos documentos, que junto a otras expresiones filosóficas y espirituales, muchos masones, individual y corporativamente, ofrecieron su aporte a la causa de la Libertad.

\section{Metodología}

Este trabajo uso una metodología cualitativa, descriptiva, producto de una revisión bibliográfica. Luego de la investigación y lectura se procedió a la selección de los materiales fundamentales que en contraste con la realidad sirven para el análisis de la influencia de la religiosidad en la arquitectura colonial y republicana.

\section{Discusión}

Algunas características de la arquitectura:

La técnica usada en las primeras iglesias y casas de madera era la de la arquitectura marinera, que permitía que los barcos oscilen entre las olas sin quebrarse. Por ello, las edificaciones guayaquileñas tendrán los empalmes en "rayos de Júpiter", para unir los pilares; "llaves", para unir las vigas, "vientos" o maderos inclinados para sujetar los pilares y "pericos" o maderos superiores para apoyar las cubiertas.

Para muebles y construcciones se usan el amarillo, el ébano, pechiche, guayacán, los robles, la madera negra, el algarrobo, el cascol, el laurel, cedro, caoba, moral fino y moral bobo. 
Los primeros templos y conventos cristianos

Los templos y sus torres también son de madera, y aquellos en forma de grandes tinglados, a excepción del Convento de Santo Domingo, que es de piedra, porque está en Ciudad Vieja, donde el terreno resiste edificios de esta materia y las Yglesias (sic) no tienen adorno.

Tres de estas iglesias eran altas, una de ellas de piedra (Santo Domingo) y todas adornadas con altares y pinturas... Algunas de las casas de la ciudad eran bastante altas, varias de ladrillo, pero la mayoría eran de madera y las más pobres de caña.

La primera parroquia o La Iglesia Matriz, empezaba en la acera Sur de la calle, hasta el fin de la ciudad. Serán 12 años más tarde, en 1887, en que el Vicario General reconocerá La Iglesia del Astillero- después - "San Alejo" como la tercera parroquia episcopal.

Esta iglesia se edificó sin duda, en el mismo lugar en que existía la iglesia de madera y techo de paja, incendiada por los corsarios el 6 de junio de 1624. En cuanto al Convento de los Padres Dominicos era como las demás casas: de madera y de caña.

Su Iglesia principal es la de San Jago o St. James, el Apóstol, que tiene 7 altares y una bonita plaza en el frente; las otras son las de San Agustín, San Francisco, Santo Domingo y San Ignacio, esta última pertenece a los jesuitas", escribe el pirata Woodes Rogers, en su "Crucero alrededor del mundo", en 1709.

La estructura invariable de la Plaza Mayor en toda ciudad colonial es esta: a un lado la Catedral, con su camposanto y solares laterales para jardines o capillas anejas. Al otro lado la casa del Corregidor. 
La plaza de la Matriz, hoy parque Seminario, se llamó en 1812 Plaza de la "Constitución” por Orden Real, que dispuso que la plaza de toda ciudad en que se jurara la Constitución española aprobada en Cádiz en ese año, se llamara de la Constitución.

Los tiempos de las primeras Galeras: la tecnología marinera que después se aplicó en las Iglesias

\section{La iglesia de Santo Domingo}

En la cumbre está la iglesia mayor y al otro lado están los astilleros. Uno de los primeros de los templos que tuvo Guayaquil, en la época de la colonia, fue el de Santo Domingo, situado en el barrio que después se llamó de Ciudad Vieja, Construido de mampostería, material adecuado a la solidez del terreno en esta parte de la ciudad, que es donde se eleva la colina del Santa Ana. Debido a la incombustibilidad de la construcción, esta iglesia colonial se salvó en gran parte en el incendio de 1896 y no fue difícil repararla poco tiempo después del desastre. Al lado de esta iglesia existe la Capilla del Rosario, de construcción moderna, sostenida por una cofradía que tiene fondos propios por erogaciones periódicas de sus afiliados y hacen servicios funerarios con oficios religiosos.

La primera construcción de la Iglesia de los Dominicos, se fundó en un suelo de tierra sólida y maciza; capáz (sic) de sostener los edificios de mayor peso de piedra, ladrillo y adobe, como se reconoce de la fábrica antigua del Convento de Santo Domingo, que subsiste todavía sin haberse pasado a Ciudad Nueva.

En el terreno cedido por el Cabildo, en el año de 1574, situado en el corto recinto llano de Ciudad Vieja, según se lee en el Plano Croquis de 1787 se comenzó a construir, en 1575, un tapial mezclado con ladrillo y piedra labrada, que sirvió como cimiento a la primera Iglesia que tuvo la ciudad, unos pedazos de muralla, y especie de reducto que dexaron (sic) empezados los primeros Fundadores. La edificación estaba hecha de madera y cubierta de hojas de cade. 
Era tradicional que en los trazados de las iglesias hubiera un huerto para la alimentación de los monjes que habitaban en el convento que rodeaba el huerto con sus galerías de madera. A más de esta función cumplía la evocación simbólica de sugerir el cultivo de las virtudes cristianas de la misma forma que se cultivan las rosas del jardín.

En el año 1624, Guayaquil sufre uno de los más crueles ataques piratas, comandado por Jacobo el Eremita Clerk, que origina un incendio general en Ciudad Vieja, quemándose totalmente la iglesia.

Los Dominicos inician su reconstrucción con los mismos materiales, sin observar las nuevas normas dictadas por el Cabildo, que disponían utilizar cubiertas de tejas, en vez de las hojas de cade, en prevención de los incendios.

Las cofradías y el cementerio de Santo Domingo

Siguiendo las ideas de las basílicas europeas, la iglesia está orientada de este a oeste, con tres naves rematadas con cubiertas en arcos de medio punto.

La iglesia lleva su nombre en recuerdo del fundador de la orden dominicana Santo Domingo de Guzmán. Las primeras edificaciones fueron de madera, piedra y adobe siendo reedificada cinco ocasiones hasta el año de 1937, en que la construyó en hormigón armado, según el proyecto del arquitecto italiano Paolo Russo.

El visitante observa una nave central con cubierta semicircular, denominada de cañón seguido y dos naves laterales de menor altura. A cada lado del altar se desarrollan dos capillas; de las cuales la de la derecha está consagrada a la veneración del Santísimo y la de la izquierda está dedicada a las ceremonias de bautismo. 
La iglesia de Santo Domingo es la única que todavía conserva el antiguo púlpito, desde donde el sacerdote pronunciaba los sermones en la época en que no había micrófono y se colocaba muy cerca del público para la predica en las misas.

Sobre el púlpito se observa un tornavoz, que permitía una mayor resonancia acústica en los sermones.

El altar de la capilla tiene dos columnas salomónicas en mármol, que simulan dos serpientes que se enroscan, evocando el capítulo del éxodo en que Moisés convirtió las espadas en serpientes en los episodios de la salida de Egipto. En la parte superior de las columnas se aprecian dos copas de los que sobresale una figura de piña en alusión a la glándula pineal. Que es la parte superior del cerebro humano como un centro de alto desarrollo espiritual. Antiguamente los Sacerdotes se cortaban el cabello en esta parte de la cabeza, lo cual recibía el nombre de tonsura.

En la parte central del atar en lo alto se observa el Cáliz o santo Grial, que evoca todo el ideal de la común unión mística del cristianismo medioeval.

El primer emplazamiento de la Iglesia Mayor

Porque es la única de muros de piedra, como edificio principal. Lo más suntuoso que en toda colonia se procuraba para la iglesia fundadora.

Porque el sitio de la Plaza Mayor o principal, no pudo ser topográficamente otro que el que ocupa Santo Domingo: lo más al fondo, adosado al cerro, al lado occidental y mirando al oriente como todo templo.

Y no pudo ser otro porque el río entonces invadía hasta lo que es hoy Paseo Colón, y por el costado mismo de la Matriz serpenteaban esterones que después se desecaron. 
La albarrada y el muelle para poder recibir adecuadamente la fiesta del Corpus Cristi

Los nativos de los alrededores tenían la costumbre de hacer pozos para sacar aguas del subsuelo; así como de llevar agua en mates.

La Iglesia Matriz estaba situada entre las calles de la Compañía, por el norte - actual Clemente Ballén - por el sur, la calle del Sagrario; por el este, la calle de La Torre, que también era llamada de la Catedral y de la Independencia - actual Chimborazo - y por el oeste, la calle Ancha o de la Soledad - actual Boyacá - donde existía el cementerio de la Iglesia.

Para que los jóvenes llamados en suerte por el Señor, se formen e instruyan, tanto en la Piedad, como en las letras humanas y sagradas, erigimos e instituimos el Seminario Eclesiástico Tridentino, en la ciudad de Guayaquil y le asignamos el edificio que está contiguo a la Iglesia de San Pedro Apóstol, hace poco elevada al Honor de Catedral.

La Plaza Principal o Plaza Mayor, estaba situada en el trazado de las ciudades coloniales españolas frente a la iglesia Matriz, ubicada en aquel entonces, entre la calle de La Torre (hoy Chimborazo) por el oeste; por el norte, la calle de la Compañía, (actual Clemente Ballén); por el este, la calle de la Caridad, (actual Chile); y por el sur, la calle de la Municipalidad, (actual 10 de Agosto).

Las casas de las Beatas

Atravesando la Plaza Mayor - actual Parque Seminario - y diagonal a la Iglesia Matriz, en la intersección de la calle de la Caridad (Chile) y la calle de la Real Cárcel (10 de Agosto), se encontraba la casa de Doña María Molina y Ayala. 
La casa de las Beatas tenía un piso alto y otro bajo, techo de tejas y paredes de madera. En los bajos funcionaban varias tiendas de comercio. No hay ventanas, sino corredores con toldas que suben y bajan según el sol y el calor.

La ojiva y la divina proporción

Uno de los elementos para reconocer el gótico clásico, es el trazado de sus pórticos ojivales. Para ello, los constructores de las catedrales del Medioevo (años 1000 hasta 1300) partieron del dibujo de una estrella (símbolo de los astros que brillan con luz propia). Hacían centro con el compás en una de sus puntas inferiores (e) y con radio e-b delineaban el primer arco. Luego con radio b-c trazaron el segundo arco. Esto hará la diferencia entre el trazado del portal de la Catedral de Guayaquil y el de imitación gótica de la Iglesia de la Merced.

Los milagros de la unidad

Mas, el lado del pentágono necesario para trazar la estrella - observaban los matemáticos - guarda con el diámetro de la circunferencia, la proporción conocida como "divina": "La totalidad es a la parte mayor, de la misma manera que ésta es a la menor". Lo que en el lenguaje de la época, equivalía a decir: "lo que es arriba es como lo que está abajo, para que se cumplan los milagros de la unidad...”

Tres siglos después, en el Renacimiento, algunos artistas como Leonardo da Vinci colaborarán con el Monje Lucca Paccioli para reconocer en estos trazados el sentido de la "divina proporción" o "número de oro" (0.618). Esta unión de las matemáticas con la alta filosofía renacentista atrajo también al pintor alemán Alberto Durero, quien acude a Italia para iniciarse en los secretos de esta nueva perspectiva. 
Los bajorrelieves de los portales

Hacia la calle Chimborazo, se pueden encontrar tres niveles de bajorrelieves que ornan el arco gótico. En el primer nivel empezando de abajo hacia arriba, aparecen las figuras de un toro, un león, un ángel y un águila; como una evocación de antiquísimas tradiciones espirituales.

Estas figuras coinciden con la representación de las estrellas fijas de la eclíptica que se encuentran en las constelaciones de Tauro (toro), Lion (león), Scorpius (águila), y Acuarios (ángel). A través de la historia, el cristianismo fue recogiendo aspectos de diversas tradiciones espirituales, expresadas en el tiempo y en la geografía, en la medida en que éstas coincidían con el mensaje del Cristo.

\section{Conclusiones}

La Conquista implicó la implantación de una fe según la visión de los conquistadores, que no siempre estuvo a la altura del auténtico mensaje crístico.

Uno de los grandes temas que tiene la historia de una colectividad es ofrecer un panorama de la dimensión espiritual de un pueblo. Este abordaje trasciende con mucho el marco de lo económico, lo político, lo social; e incluso lo religioso, para contemplar un conjunto de ideas acerca del universo y de la vida, que han ido dejando su huella en el espacio urbano y en las expresiones de la arquitectura.

El desconocimiento de la tradición espiritual de un pueblo, equivale a una ruptura y desmembramiento de su identidad. La esperanza de recuperación del significado, plasmado algunas veces en la arquitectura, ondea como una fuerza unificadora para iluminar el porvenir y comprender la vida en su totalidad. 
La religiosidad y la arquitectura en la colonia y la república

\section{Bibliografía}

Actas del Cabildo Colonial, Tomo IV, Archivo Histórico del Guayas, 1974

De Cieza De León, Pedro, La Crónica del Perú, Editorial Cofás, S.A., España, 2000.

Destruge Camilo, Álbum Biográfico Ecuatoriano, Tomo I - II, Banco Central del Ecuador, Guayaquil, 1984.

De La Vega Garcilaso, Comentarios Reales, Editorial Porrua, México, 2013.

Iturralde José Antonio, Crónicas, Relatos y Estampas de Guayaquil, Archivo Histórico del Guayas, 2006.

Laviana María Luisa, Guayaquil en el siglo XVIII Guayaquil, Archivo Histórico del Guayas, 2002.

ZiolkowskI Mariusz S., Sadowski Robert M., La Arqueoastronomía en las Investigaciones de las Culturas Andinas, Banco Central del Ecuador Instituto Otavaleño de Antropología, Quito, 1992. 